Check for updates

Cite this: RSC Adv., 2018, 8, 13750

Received 17th February 2018

Accepted 2nd April 2018

DOI: $10.1039 / c 8 r a 01490 f$

rsc.li/rsc-advances

\section{Synthesis of HKUST-1 and zeolite beta composites for deep desulfurization of model gasoline $\dagger$}

\author{
Xue Liang, ${ }^{a}$ Ying Zhang, (D) *ab Yuanyuan Qu, ${ }^{a}$ Yang Han, ${ }^{a}$ Xilong Wang, ${ }^{b}$ \\ Achao Cheng, ${ }^{\mathrm{a}}$ Aijun Duan (D) ${ }^{\mathrm{b}}$ and Liang Zhao (DD ${ }^{\mathrm{b}}$
}

Composites of zeolite beta microspheres@nanosized HKUST-1 and micro-octahedron-shaped HKUST1ananosized zeolite beta were fabricated to remove thiophene from model oil. The two composite materials exhibited a higher adsorption capacity and faster adsorption rate than their corresponding mechanical mixture of HKUST-1 and zeolite beta when the sulfur concentration was at around 100 ppmw.
In recent years, air pollution due to the emission of $\mathrm{SO}_{x}$ exhaust gases from transportation fuel has become of major concern to mankind. To minimize the negative health and environmental effects of the exhaust gases, deep desulfurization for the production of ultra-clean fuels is necessary and urgent. ${ }^{1-3}$ Several new technologies have been explored to meet the demand for ultra-clean fuels. ${ }^{4-6}$ Among these, adsorptive desulfurization (ADS) has been considered as a promising method for reducing the sulfur content of fuels, due to its low cost and mild conditions. ${ }^{3,4}$ So far, various types of adsorbents have been reported for desulfurization, such as metal oxides, active carbon, clays, mesoporous materials, zeolites and metalorganic frameworks. ${ }^{2,7-13}$ The metal-organic framework HKUST1 is reported to have a high adsorption capacity, but its high price and poor stability are unfavorable for application. Zeolite beta has a fast adsorption rate, but its adsorption capacity is low. In this paper, we report for the first time the synthesis of two kinds of HKUST-1 and zeolite beta composites as adsorbents for the removal of aromatic sulfur compounds from model gasoline, aiming to make full use of their respective advantages.

One of the two composites that has been synthesized is HKUST-1@nanosized zeolite beta (designated as HKNB). A HKUST-1 mother liquor was heated at $120^{\circ} \mathrm{C}$ for $24 \mathrm{~h}$, and then pre-synthesized nanosized zeolite beta and P123 were successively added to the HKUST-1 reaction mixture. The mixture was finally heated at $120^{\circ} \mathrm{C}$ for $12 \mathrm{~h}$ (for full details see Scheme 1a and S4 in the ESI + ). Pristine HKUST-1 has an octahedral shape with sharp edges with an average diameter of approximately 18 $\mu \mathrm{m}$ (Fig. 1a). Nanosized zeolite $\mathrm{H}$-beta was crystallized at $120^{\circ} \mathrm{C}$

${ }^{a}$ Department of Materials Science and Engineering, China University of Petroleum (Beijing), Changping District, Beijing 102249, China. E-mail: Y.Zhang@cup.edu.cn ${ }^{b}$ The State Key Laboratory of Heavy Oil Processing, China University of Petroleum (Beijing), Changping District, Beijing 102249, China

$\dagger$ Electronic supplementary information (ESI) available. See DOI: 10.1039/c8ra01490f for $24 \mathrm{~h}$ within the pores of polystyrene microspheres (see Fig. S3 in the ESI $\dagger$ ). The as-synthesized zeolite beta nanoparticles (designated as NB) have a well-defined spherical morphology and are highly dispersed with an average diameter of approximately $300 \mathrm{~nm}$ (Fig. 1b). As shown in Fig. 1c, NB is uniformly distributed on the surface of HKUST-1, forming a core-shell structure.

The other composite is zeolite beta microspheres@HKUST-1 (designated as HKMB), which was synthesized through a stepby-step seeding procedure (for full details see Fig. S4 in the ESI $\dagger$ ). Zeolite $\mathrm{H}$-beta microspheres were dipped, in sequence, in (a) a $\mathrm{Cu}\left(\mathrm{CH}_{3} \mathrm{COO}\right)_{2} \cdot 3 \mathrm{H}_{2} \mathrm{O}$ ethanol solution for $20 \mathrm{~min}$, (b) ethanol for $5 \mathrm{~min}$, (c) a trimesic acid $\left(\mathrm{H}_{3} \mathrm{BTC}\right)$ ethanol solution for $40 \mathrm{~min}$, and (d) ethanol for $5 \mathrm{~min}$. In step (a) the $\mathrm{Cu}$ ions were exchanged with zeolite $\mathrm{H}$-beta spheres and the carboxyl groups of $\mathrm{H}_{3} \mathrm{BTC}$ were bonded with $\mathrm{Cu}^{2+}$ during step (c). The processes from step (a) to step (d) represent a cycle. After cycling several times, the zeolite beta spheres with a seed layer were dried at $60{ }^{\circ} \mathrm{C}$ for $30 \mathrm{~min}$. After drying, they were added to the HKUST- 1 mother liquor and heated at $120^{\circ} \mathrm{C}$. The procedure is shown in Scheme $1 \mathrm{~b}$.

Zeolite H-beta microspheres (designated as MB) were crystallized from clear homogeneous solutions within the pores of anion-exchange resin beads ${ }^{14}$ (see Fig. S3 in the ESI $\dagger$ ), and the average diameter of MB is about $550 \mu \mathrm{m}$. From Fig. $1 \mathrm{~d}-\mathrm{f}$, it can be seen that nanosized HKUST-1 is distributed uniformly on the surface of MB. Moreover, HKUST-1 is not only loaded on the surface but also in the pore channels of the MB beads (see Fig S1-S3 in the ESI $\dagger$ ). Besides, the color change from white for bare MB to blue for HKMB (see Fig S4 in the ESI $\dagger$ ) is strong evidence of the successful loading of HKUST-1 on MB. It is worth noting that without the step-by-step seeding procedure, HKUST-1 can hardly be loaded on MB.

Fig. 2a shows the powder X-ray diffraction (PXRD) patterns of the different samples. The main diffraction peaks of HKNB are well matched with those of as-synthesized HKUST-1, and no obvious PXRD peaks of zeolite beta nanoparticles can be 
(a)
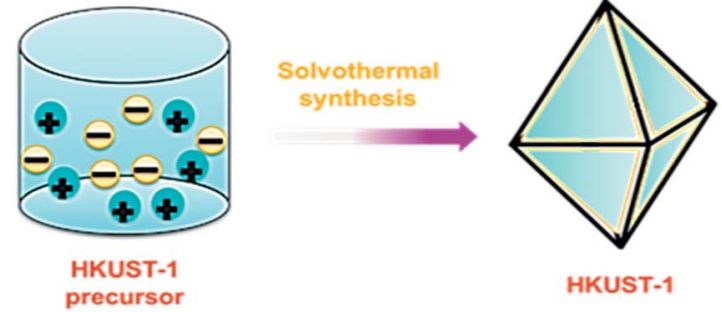

HKUST-1
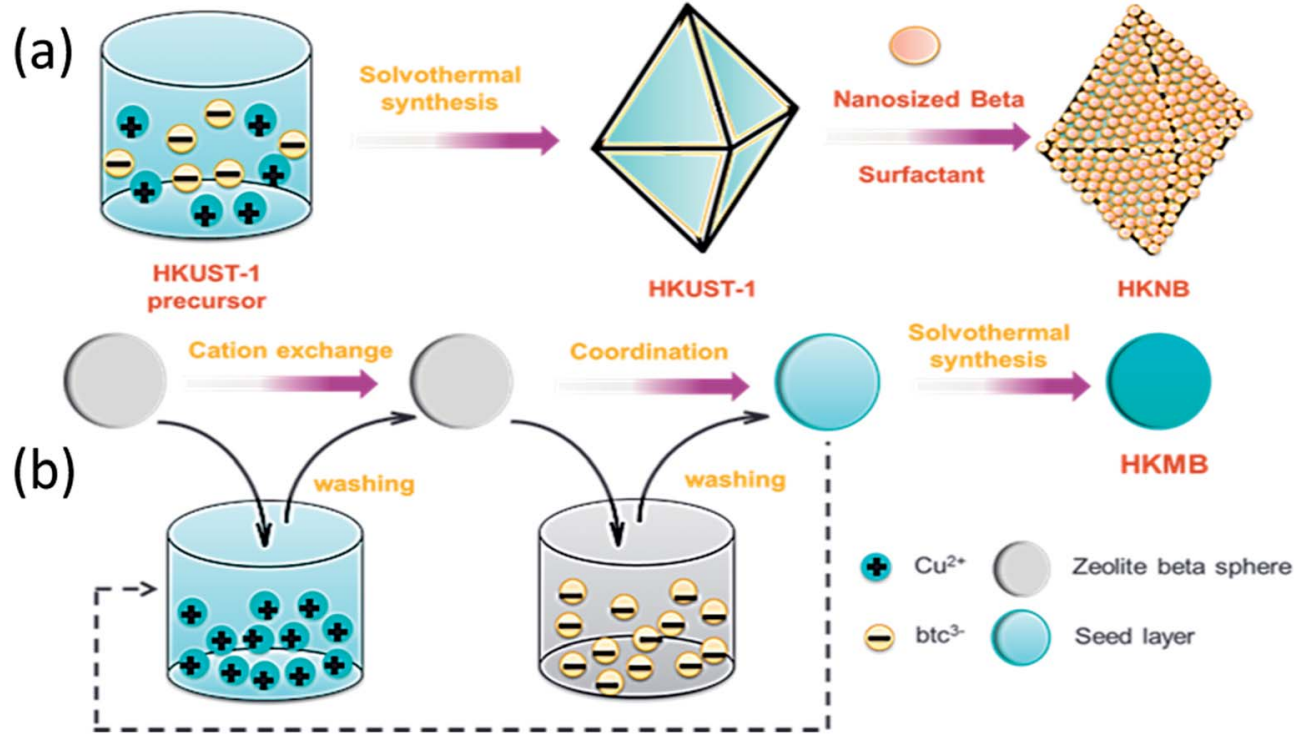

Scheme 1 Schematic illustration of the synthesis procedure of HKNB and HKMB.

detected, which is attributed to the low content of NB in the HKNB composite as well as an overlap of the peaks. Unlike HKNB, the PXRD pattern of HKMB shows relatively strong peaks at $2 \theta \approx 7.5^{\circ}$ and $22.4^{\circ}$, which are attributed to the (101) and (302) reflections of zeolite beta and a few weak intensity peaks at $2 \theta$ values of $9.5^{\circ}, 11.7^{\circ}, 17.5^{\circ}$ and $19.0^{\circ}$, which are associated with the HKUST-1 structure. ${ }^{15,16}$ These results signify the successful growth of HKUST-1 on/in MB in HKMB.

The samples were further characterized by FT-IR spectroscopy and the results are shown in Fig. 2 b. For zeolite beta, the wavenumbers at $820-750 \mathrm{~cm}^{-1}$ represent the $\mathrm{O}-\mathrm{T}-\mathrm{O}(\mathrm{T}=\mathrm{Si}, \mathrm{Al})$ symmetric stretching vibration, while the peaks at $1092 \mathrm{~cm}^{-1}$ and $1224 \mathrm{~cm}^{-1}$ belong to the external and internal asymmetric stretching vibrations of the $\mathrm{Si}-\mathrm{O}(\mathrm{Al})$ bonds. ${ }^{17,18}$ The absorption bands at 455,525 and $575 \mathrm{~cm}^{-1}$ are characteristic of zeolite beta. ${ }^{19,20}$ The broad band in the $3500-3300 \mathrm{~cm}^{-1}$ region confirms the presence of the OH groups in zeolite beta. The IR spectrum of HKUST-1 is in good agreement with that reported in the literature. ${ }^{21}$ The absorption bands at $1645 \mathrm{~cm}^{-1}$, $1565 \mathrm{~cm}^{-1}, 1450 \mathrm{~cm}^{-1}$ and $1375 \mathrm{~cm}^{-1}$ are assigned to the asymmetric and symmetric stretching vibrations of the carboxylate groups in BTC, respectively. The peaks in the lower wavenumber region of $1300-700 \mathrm{~cm}^{-1}$ can be attributed to the out-of- plane vibrations of BTC, and an obvious absorption peak at $500 \mathrm{~cm}^{-1}$ can be ascribed to the $\mathrm{Cu}-\mathrm{O}$ stretching vibrations. ${ }^{22}$ Both HKNB and HKMB possess similar main characteristic peaks of HKUST-1 and zeolite beta, proving the successful synthesis of the HKUST-1 and zeolite beta composites.

The thermogravimetric analysis results are shown in Fig. 2c. In the case of zeolite beta, the weight loss is due to the release of
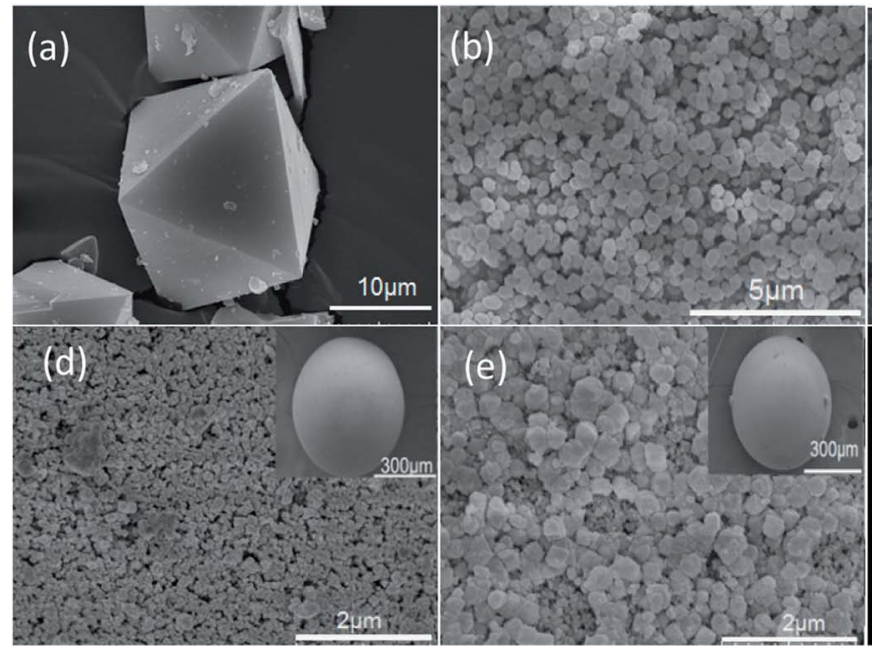

(c)

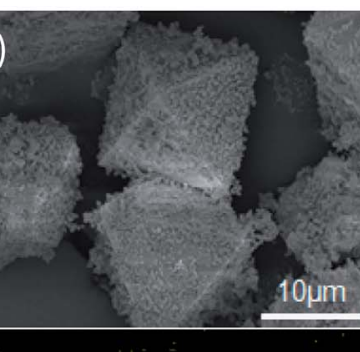

(f)

Fig. 1 SEM images of (a) HKUST-1, (b) NB, (c) as-prepared HKNB, (d) the MB surface [(inset) MB], (e) the HKMB surface [(inset) HKMB] and (f) the EDX mapping of the Cu in HKMB. 

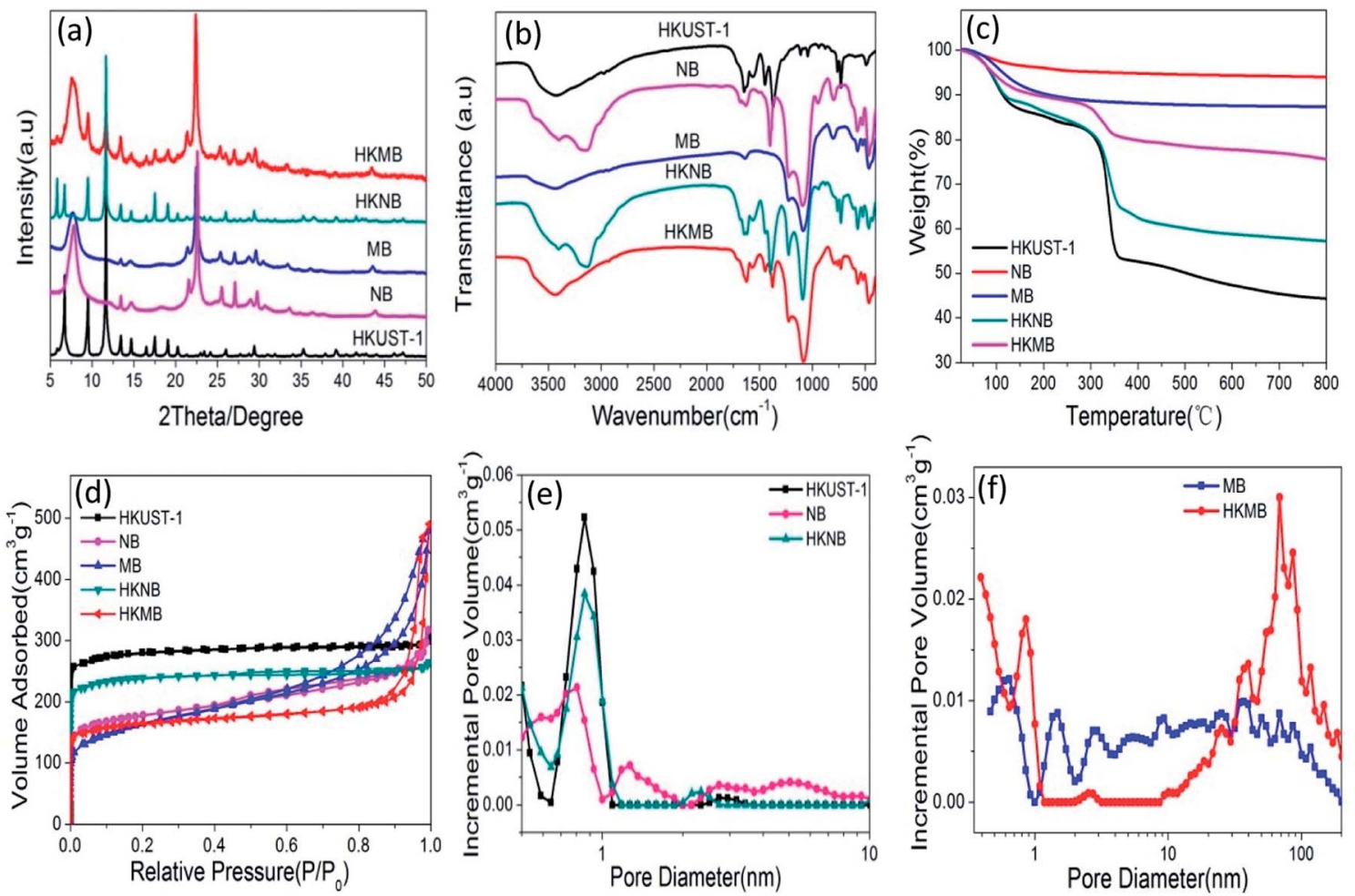

Fig. 2 (a) PXRD patterns, (b) FT-IR spectra, (c) TG curves, (d) $\mathrm{N}_{2}$ adsorption-desorption isotherms and (e, f) pore size distributions using DFT analysis of HKUST-1, NB, MB, HKNB and HKMB.

water. For HKUST- 1 and the two composites, below $300{ }^{\circ} \mathrm{C}$, the weight losses can be ascribed to the elimination of free water, guest molecules and crystallization water, respectively. The sharp weight losses occurring at $350{ }^{\circ} \mathrm{C}$ are derived from the decomposition of organic ligands (BTC), which suggests the collapse of the HKUST-1 framework. Based on the thermogravimetric analysis, the loadings of HKUST- 1 were calculated to be $68.5 \mathrm{wt} \%$ and $34.3 \mathrm{wt} \%$ in HKNB and HKMB, respectively.

The textural properties of the five samples were further studied and the $\mathrm{N}_{2}$ adsorption-desorption isotherms are shown in Fig. 2d. The isotherm for HKUST-1 is of type I with a small hysteresis loop, indicating the microporous character of the framework, with $0.9 \mathrm{~nm}$ by $0.9 \mathrm{~nm}$ square channels. ${ }^{23}$ The hysteresis loop may originate from a small portion of mesopores produced by the aggregation of small HKUST-1 crystals. For both zeolite beta and the composites, the isotherms are a combination of type I and type IV and there are type $\mathrm{H} 2$ hysteresis loops at lower relative pressures, indicating the coexistence of micropores and mesopores. ${ }^{14,24}$ The BET surface areas (Table 1) of the samples concerned decrease in the order of HKUST-1 > HKNB > NB > MB > HKMB. For HKNB, although the loading of NB makes the BET surface area decrease to some extent, the value still remains at a high level $\left(808.13 \mathrm{~m}^{2} \mathrm{~g}^{-1}\right)$. The BET surface area of HKMB is less than those of HKUST-1 and MB because HKUST-1 occupies the internal channels of the MB crystals in HKMB. The pore size distributions of the five samples are shown in Fig. 2e and f. Compared with HKUST-1, which has micropores that are mainly concentrated at around $0.86 \mathrm{~nm}$, with a small amount of mesopores at $3.65 \mathrm{~nm}$, HKNB has fewer micropores at $0.86 \mathrm{~nm}$ due to it having less HKUST-1 content. For HKMB, the mesopore size is larger than that in MB, while the pore volume is smaller than that in $\mathrm{MB}$, which is due to the loading of HKUST-1 in the channels and on the surfaces of the MB microspheres (see Fig. 2 and Table 1). More

Table 1 Texture properties of the samples calculated from nitrogen adsorption isotherms

\begin{tabular}{|c|c|c|c|c|c|c|c|}
\hline Sample & $S_{\mathrm{BET}}^{a}\left(\mathrm{~m}^{2} \mathrm{~g}^{-1}\right)$ & $S_{\text {micro }}^{b}\left(\mathrm{~m}^{2} \mathrm{~g}^{-1}\right)$ & $S_{\text {meso }}\left(\mathrm{m}^{2} \mathrm{~g}^{-1}\right)$ & $V_{\text {pore }}\left(\mathrm{cm}^{3} \mathrm{~g}^{-1}\right)$ & $V_{\text {mico }}^{b}\left(\mathrm{~cm}^{3} \mathrm{~g}^{-1}\right)$ & $V_{\text {meso }}\left(\mathrm{cm}^{3} \mathrm{~g}^{-1}\right)$ & Pore size $(\mathrm{nm})$ \\
\hline HKUST-1 & 941.14 & 874.47 & 66.67 & 0.481 & 0.405 & 0.076 & 2.04 \\
\hline NB & 605.82 & 416.02 & 189.8 & 0.491 & 0.192 & 0.299 & 3.24 \\
\hline HKNB & 808.13 & 747.97 & 60.16 & 0.409 & 0.344 & 0.065 & 2.03 \\
\hline HKMB & 557.23 & 457.01 & 100.22 & 0.759 & 0.211 & 0.548 & 5.45 \\
\hline
\end{tabular}

${ }^{a}$ BET method. ${ }^{b} t$-Plot method. 
(a)

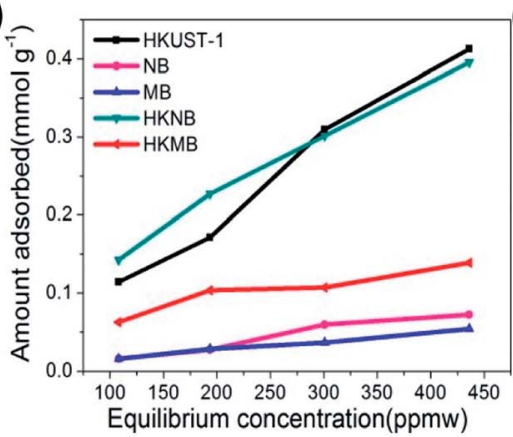

(b)

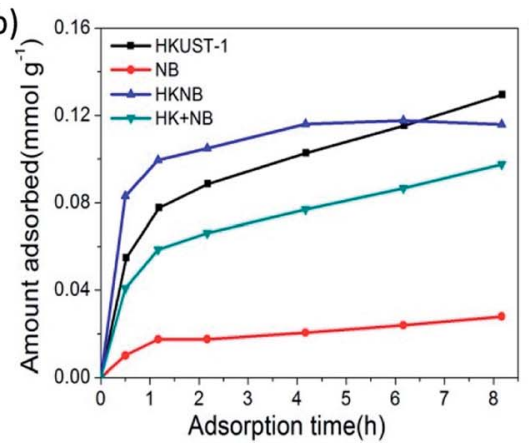

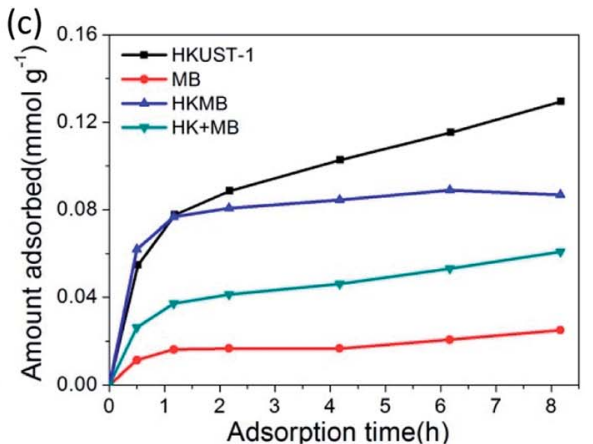

Fig. 3 (a) Adsorption capacities of thiophene on the adsorbents. Reaction conditions: model oil, $2 \mathrm{~mL}$; adsorbents, $20 \mathrm{mg}$; reaction time, $4.7 \mathrm{~h}$; room temperature. (b) and (c) the effect of time on the adsorption desulfurization capacity for thiophene over different adsorbents. Reaction conditions; model oil, $2 \mathrm{~mL}$; adsorbents, 20 mg; S-concentration, 100 ppmw; room temperature.

importantly, the existence of micropores at $0.86 \mathrm{~nm}$ in HKMB is also strong evidence that HKUST-1 has been successfully loaded on $\mathrm{MB}$.

To study the adsorption performance of HKNB and HKMB, the adsorption isotherms of thiophene from isooctane solution, with a sulfur content ranging from about 100 to $440 \mathrm{ppmw}$, are plotted in Fig. 3a. The effects of time on the adsorption desulfurization capacity for thiophene over different adsorbents at a sulfur concentration of about 100 ppmw are given in Fig. 3b and c. For comparison, two mechanical mixture samples were made by mixing $68.5 \%$ HKUST- 1 and $31.5 \%$ NB (marked as HK $+\mathrm{NB}$ ), and $34.3 \%$ HKUST-1 and $65.7 \%$ MB (marked as HK + $\mathrm{MB})$, respectively. For aromatic sulfur compound adsorption, three factors should be considered: (1) the acid-base interaction between the adsorbent and adsorbate; ${ }^{25,26}(2)$ the $\pi$-complexation interaction between the metal sites and the delocalized $\pi$ electrons of the aromatic ring; ${ }^{27-29}$ (3) the pore structure of the adsorbent. ${ }^{27,30,31}$ Fig. 3a reveals that the adsorption capacities for thiophene increase in the order of $\mathrm{MB}<\mathrm{NB}<\mathrm{HKMB}<\mathrm{HKNB}$ $<$ HKUST-1 when the sulfur concentration is higher than 300 ppmw. The adsorption capacities of $\mathrm{NB}$ and $\mathrm{MB}$ for thiophene are negligible. Compared with the composites, HKUST-1 has the highest adsorption capacity for thiophene.

This is because HKUST- 1 has a lot of unsaturated $\mathrm{Cu}^{2+}$ metal centers after the heat and vacuum treatment, which act as a Lewis acid and can adsorb alkaline thiophene through an acid-base interaction. ${ }^{24}$ Therefore, the adsorption capacity of the composites decreases with a decrease in the HKUST-1 content. However, when the sulfur concentration is below 300 ppmw, HKNB has a higher adsorption capacity than that of HKUST-1. For example, HKNB has an adsorption capacity of $0.14 \mathrm{mmol} \mathrm{S} \mathrm{g}^{-1}$ at $108 \mathrm{ppmw}$, which is higher than the $0.11 \mathrm{mmol} \mathrm{S} \mathrm{g}^{-1}$ for bare HKUST-1. This can be explained from Fig. $3 \mathrm{~b}$, which shows that the adsorption amounts of all of the HKUST-1-containing samples increase sharply over the first $2 \mathrm{~h}$ of adsorption desulfurization, and that the adsorption rate of HKNB is faster than those of HKUST-1 and HK + NB. This could be due to a synergistic effect between HKUST-1 and zeolite beta. The adsorption of zeolite beta nanoparticles enveloped over the HKUST-1 crystals causes the enrichment of thiophene around
HKUST-1, resulting in a higher thiophene concentration around HKUST-1 than that in the solution, and thus accelerating the adsorption rate of HKUST-1 for thiophene in HKNB. After $4 \mathrm{~h}$, the adsorption desulfurization reaches equilibrium and remains stable for HKNB, but the adsorption capacities of HKUST-1 and HK + NB still to rise because the adsorption of HKUST-1 has not reached the saturation point. As seen from Fig. 3c, HKMB has a higher adsorption capacity $(0.06 \mathrm{mmol} \mathrm{S}$ $\left.\mathrm{g}^{-1}\right)$ than those of MB $\left(0.01 \mathrm{mmol} \mathrm{S} \mathrm{g}^{-1}\right), \mathrm{HK}+\mathrm{MB}(0.03 \mathrm{mmol} \mathrm{S}$ $\left.\mathrm{g}^{-1}\right)$ and HKUST-1 $\left(0.05 \mathrm{mmol} \mathrm{S} \mathrm{g}^{-1}\right)$ after the first $1 \mathrm{~h}$, and a faster adsorption rate, reaching its saturated adsorption amount faster than HKUST-1, which may attributed to the loading and high dispersivity of nanosized HKUST-1, as well as the existence of mesopores. ${ }^{32}$ In addition, HKMB can be recycled easily using a simple decantation method.

In summary, HKMB and HKNB have been successfully prepared using a step-by-step seeding approach and a solvothermal method, respectively, and they were used to remove thiophene from a model gasoline isooctane solution. Both of the samples showed a higher adsorption capacity and faster adsorption rate than their corresponding mechanical mixtures of HKUST- 1 and zeolite beta when the concentration of sulfur was at about 100 ppmw due to synergistic effects between HKUST-1 and zeolite beta. HKNB had an even faster adsorption rate and a comparable amount of adsorption capacity than HKUST- 1 when the concentration of sulfur was less than 300 ppmw. HKMB can be recycled easily using a simple decantation method. This research opens up synthetic pathways to an extensive number of zeolite and MOF composites for desulfurization and other potential applications in the future.

\section{Conflicts of interest}

There are no conflicts to declare.

\section{Acknowledgements}

We acknowledge the National Natural Science Foundation of China (No. 21676296) and the National Key Research and Development Plan (Grant No. 2016YFC0303700) for supporting this work. 


\section{Notes and references}

1 C. Song and X. Ma, Appl. Catal., B, 2003, 41, 207-238.

2 J. H. Kim, X. Ma, A. Zhou and C. Song, Catal. Today, 2006, 111, 74-83.

3 R. Dehghan and M. Anbia, Fuel Process. Technol., 2017, 167, 99-116.

4 F. Tian, Z. Fu, H. Zhang, J. Zhang, Y. Chen and C. Jia, Fuel, 2015, 158, 200-206.

5 M. T. Timko, J. A. Wang, J. Burgess, P. Kracke, L. Gonzalez, C. Jaye and D. A. Fischer, Fuel, 2016, 163, 223-231.

6 A. S. Ogunlaja, R. S. Walmsley, C. du Sautoy, N. Torto and Z. R. Tshentu, Energy Fuels, 2013, 27, 7714-7723.

7 Y. Shi, W. Zhang, H. Zhang, F. Tian, C. Jia and Y. Chen, Fuel Process. Technol., 2013, 110, 24-32.

8 J. C. Zhang, L. F. Song, J. Y. Hu, S. L. Ong, W. J. Ng, L. Y. Lee and R. Y. Ma, Energy Convers. Manage., 2005, 46, 1-9.

9 V. Selvavathi, V. Chidambaram, A. Meenakshisundaram, B. Sairam and B. Sivasankar, Catal. Today, 2009, 141, 99-102.

10 W. Ahmad, I. Ahmad, M. Ishaq and K. Ihsan, Arabian J. Chem., 2014, 50, 543-549.

11 S. Mikhail, T. Zaki and L. Khalil, Appl. Catal., A, 2002, 227, 265-278.

12 B. S. Liu, D. F. Xu, J. X. Chu, W. Liu and C. T. Au, Energy Fuels, 2007, 21, 250-255.

13 S. Qiu, M. Xue and G. Zhu, Chem. Soc. Rev., 2014, 43, 61166140.

14 L. Tosheva, B. Mihailova, V. Valtchev and J. Sterte, Microporous Mesoporous Mater., 2001, 48, 31-37.

15 W. Sun, L. Wang, X. Zhang and G. Liu, Microporous Mesoporous Mater., 2015, 201, 219-227.

16 K. Schlichte, T. Kratzke and S. Kaskel, Microporous Mesoporous Mater., 2004, 73, 81-88.
17 F. Cao, Y. Wu, J. Gu and J. Wang, Mater. Chem. Phys., 2011, 130, 727-732.

18 Z. L. Cheng, Y. X. Li and Z. J. Liu, J. Alloys Compd., 2017, 708, 255-263.

19 B. J. Schoeman, E. Babouchkina, S. Mintova, V. P. Valtchev and J. Sterte, J. Porous Mater., 2001, 8, 13-22.

20 G. Huang, P. Ji, H. Xu, J. G. Jiang, L. Chen and P. Wu, Microporous Mesoporous Mater., 2017, 248, 30-39.

21 C. Petit, J. Burress and T. J. Bandosz, Carbon, 2011, 49, 563572.

22 E. Borfecchia, S. Maurelli, D. Gianolio, E. Groppo, M. Chiesa, F. Bonino and C. Lamberti, J. Phys. Chem. C, 2012, 116, 19839-19850.

23 S. S. Y. Chui, S. M. F. Lo, J. P. Charmant, A. G. Orpen and I. D. Williams, Science, 1999, 283, 1148-1150.

24 P. Tan, X. Y. Xie, X. Q. Liu, T. Pan, C. Gu, P. F. Chen and L. B. Sun, J. Hazard. Mater., 2017, 321, 344-352.

25 F. Shi, M. Hammoud and L. T. Thompson, Appl. Catal., B, 2011, 103, 261-265.

26 S. H. Jhung, N. A. Khan and Z. Hasan, CrystEngComm, 2012, 14, 7099-7109.

27 H. Chen, Y. Wang, F. H. Yang and R. T. Yang, Chem. Eng. Sci., 2009, 64, 5240-5246.

28 A. J. Hernández-Maldonado and R. T. Yang, AIChE J., 2004, 50, 791-801.

29 A. J. Hernández-Maldonado, S. D. Stamatis, R. T. Yang, A. Z. He and W. Cannella, Ind. Eng. Chem. Res., 2004, 43, 769-776.

30 F. Tian, X. Yang, Y. Shi, C. Jia, Y. Chen and J. Nat, J. Nat. Gas Chem., 2012, 21, 647-652.

31 W. Li, Q. Liu, J. Xing, H. Gao, X. Xiong, Y. Li and H. Liu, AIChE J., 2007, 53, 3263-3268.

32 L. Qin, Y. Zhou, D. Li, L. Zhang, Z. Zhao, Z. Zuhra and C. Mu, Ind. Eng. Chem. Res., 2016, 55, 7249-7258. 